José Labarère Bertrand Renaud Michael J. Fine

\section{Erratum to: How to derive and validate clinical prediction models for use in intensive care medicine}

Published online: 22 March 2014

(C) Springer-Verlag Berlin Heidelberg and ESICM 2014

The online version of the original article can be found under doi:10.1007/s00134-014-3227-6.

J. Labarère

Quality of Care Unit, University Hospital, Grenoble 38043, France

J. Labarère

TIMC UMR 5525 CNRS, Université Joseph Fourier-Grenoble 1,

Grenoble, France

B. Renaud

Emergency Department, Cochin and Hôtel Dieu Hospitals, Assistance Publique-Hôpitaux de Paris (AP-HP), Paris, France

B. Renaud

Faculté de Médecine Paris Descartes, Paris, France

\section{J. Fine}

Veterans Affairs Center for Health Equity and Research Promotion, VA Pittsburgh Healthcare System, Pittsburgh, PA, USA

\section{J. Fine}

Division of General Internal Medicine, University of Pittsburgh Medical Center, Pittsburgh, PA, USA

J. Labarère (®)

UQEM, Pavillon Taillefer, CHU BP217, Grenoble 38043, Grenoble Cedex 9, France

e-mail: JLabarere@chu-grenoble.fr; jose.labarere@laposte.net Tel.: +33-4-76768767

Fax: +33-4-76768831

\section{Erratum to: Intensive Care Med} DOI 10.1007/s00134-014-3227-6

The given name and family name of the second author, Bertrand Renaud, were transposed in the manuscript supplied for publication. 